\title{
Social deprivation and novelty effects on gregarious behavior in the rat
}

\author{
BEN D. MONROE \\ Smoky Mountain Mental Health Center, Cullowhee, North Carolina 28723 \\ and \\ JOEL S. MILNER \\ Western Carolina University, Cullowhee, North Carolina 28723
}

\begin{abstract}
Forty male rats were maintained for 60 days in isolated $(\mathrm{N}=20)$ or paired $(\mathrm{N}=20)$ housing conditions. Beginning at 87 days of age, subject pairs from the same housing condition were tested for gregarious behavior in a circular open field over a 7-day test period. On each test day, half of the subjects within each housing condition were paired with the same animal and half of the subjects were paired with a different animal. The results indicated rats housed in isolation are more gregarious than rats housed in pairs. Across test days gregarious behavior increased. In addition, gregariousness increased for those subjects which were paired with a different conspecific on each test day. This finding suggests that partner novelty, as well as housing conditions, are factors which can influence gregarious behavior.
\end{abstract}

Studies on the effects of housing conditions on gregarious behavior in the rat have produced contrasting results. Investigators report individual and group housing have no effect on gregarious behavior (Bayroff, 1936), individual housing increases gregarious behavior (Latané, Cappel, \& Joy, 1970; Latané, Schneider, Waring, \& Zweigenhaft, 1971; Salazar, 1968; Shelley \& Hoyenga, 1966; Sloan \& Latané, 1974), and group housing increases gregarious behavior (Ashida, 1964; Stevenson \& Simmel, 1967).

Latané et al. (1970) have suggested gregariousness has drive-like characteristics and is responsive to deprivation. In addition, since an encounter with a conspecific would be a more novel experience for a rat housed in isolation than for one housed in a group, a novelty or curiosity factor, as well as deprivation, may be involved in any increase in gregariousness. Latané et al. (1971) reported that, while isolated subjects were more gregarious than pair-housed subjects, there were no differences in gregarious behavior between novel and familiar conspecific test pairs. Barefoot, Aspey, and Olson (1975) also investigated the effect of partner novelty on gregarious behavior. They reported both individual housing and conspecific novelty increase affiliation. While Barefoot et al. (1975) conclude a novelty factor exists, in contrast to Latané et al. (1971), the statistical analysis of their experiment which employed Latane's open-field measurement technique yielded no significant novelty effects. As a consequence of the need for more data, the present study employed Latane's open-field technique to investigate the effects of rearing conditions and novelty on gregarious behavior.

\section{METHOD}

\section{Subjects}

The subjects were 40 male Sprague-Dawley albino rats. The animals were received at 28 days of age and were assigned randomly to one of two housing conditions: individual $(\mathrm{N}=20)$ and paired $(N=20)$. Partitions were placed between the individual cages to prevent visual contact between subjects in different cages. Laboratory chow and water were provided ad lib.

\section{Apparatus}

The test apparatus was a circular open field $1.22 \mathrm{~m}$ in diam with a .46-meter wall. The field was painted flat black and divided by white lines into 49 sections of equal size and roughly equivalent shape by a series of concentric circles and radii. Each section was labeled with a number from 1 to 49 to facilitate the designation of an animal's position within the field (Latane, 1969).

\section{Procedure}

Familiarization trials were begun at 78 days of age. During the trials, each subject was allowed individually to explore the test apparatus for $5 \mathrm{~min} /$ day for 7 consecutive days. Gregarious testing began when the rats were 87 days of age and was carried out over the following 7 days. A test trial consisted of placing two like-reared non-cagemate subjects in the open field for $5 \mathrm{~min} /$ day. On each trial, 10 of the pair-reared subjects were paired with the same subject [paired-same group (Ps)] and 10 of the pair-reared subjects were paired with a different subject [paired-different group (Pd)]. Similarly, on each trial, 10 individually reared subjects were paired with the same subject [individual-same group (Is)] and 10 individually reared subjects were paired with a different subject [individual-different group (Id)]. During each test trial, the position of each subject was recorded at $10-\sec$ intervals. This positional time-sampling technique permitted the attainment of an estimate of the mean distance between subjects during each trial.

\section{RESULTS}

The mean distance in centimeters between subject pairs as a function of housing conditions, novelty, and trials is presented in Figure 1. A three-factor analysis of variance with repeated measures on the third factor (Winer, 1962) indicated significant differences for 


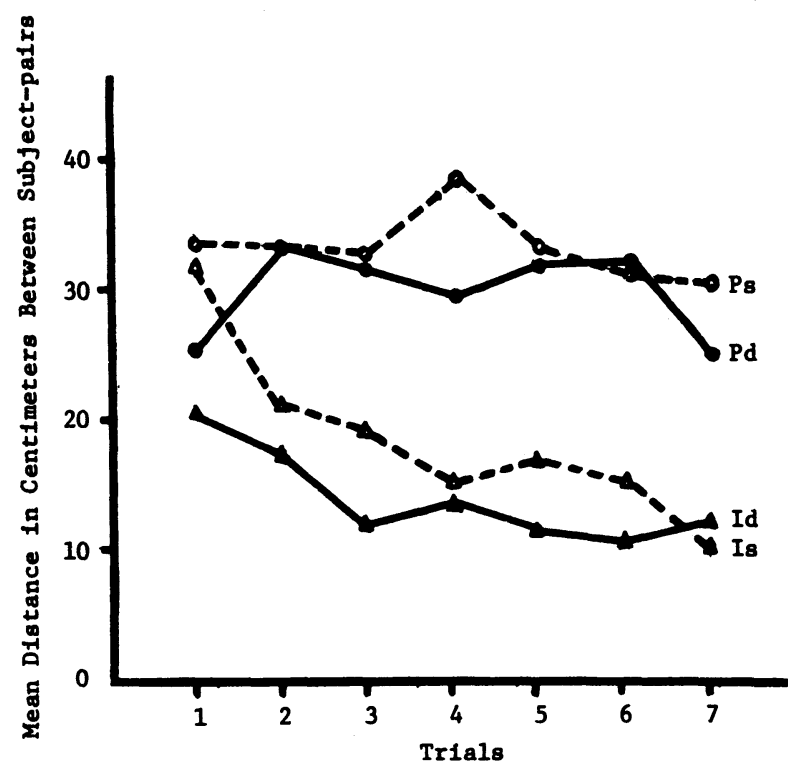

Figure 1. Mean distance between subject pairs as a function of housing conditions and trials.

housing conditions $(\mathrm{df}=1 / 16, \mathrm{~F}=31.93, \mathrm{p}<.001)$, novelty $(\mathrm{df}=1 / 16, \mathrm{~F}=6.49, \mathrm{p}<.05)$, and trials $(\mathrm{df}=6 / 96, \mathrm{~F}=4.76, \mathrm{p}<.01)$. The interaction of Housing Conditions by Trials was also significant $(\mathrm{df}=6 / 96, \mathrm{~F}=4.89, \mathrm{p}<.01)$. No other interactions were significant.

\section{DISCUSSION}

The present finding that rats housed individually are more gregarious than rats housed in pairs is consistent with the reports of Latané et al. (1970), Salazar (1968), Shelley and Hoyenga (1966), and Sloan and Latané (1974). An increase in gregariousness was observed across trials. Again, these data support previous reports (Barefoot et al., 1975; Sloan \& Latané, 1974).

Gregariousness also appears to be affected by a novelty factor. That is, rats were more affiliative when they were tested with unfamiliar than with familiar conspecifics. In contrast, Latané et al. (1971) reported no novelty effect, and Barefoot et al. (1975) reported trends toward a novelty effect only when using Latane's open-field technique. While these different results are not easily explained, there are several design differences which might be noted. The animals in the present study were housed in isolation or in pairs for approximately 60 days, while Latané et al. (1971) housed subjects for only 5 or 6 days under various conditions and Barefoot et al. (1975) housed animals for approximately 15 days under isolated and paired conditons.

Barefoot et al. (1975) found a trend for individually housed subjects to be more affiliative with unfamiliar partners than with familiar conspecifics. Although the partner novelty by housing condition was not significant in the present study, a trend was present. The data in Figure 1 show some support for the contention that isolated subjects respond more than nonisolated subjects to novel partners. If the effects of novelty are seen more readily in the isolated subject paired with an unfamiliar conspecific, then the length of the isolation period may be an importnat factor.

\section{REFERENCES}

Asmida, S. Modification by early experience of the tendency towards gregariousness in rats. Psychonomic Science, 1964, 1, 343-344.

Barefoot, J. C., Aspey, W. P., \& Olson, J. M. Effects of partner novelty on affiliation in the rat. Bulletin of the Psychonomic Society, 1975, 6, 655-657.

BAYROFF, A. G. The experimental social behavior of animals: I. The effect of early isolation of white rats on their later reaction to other white rats measured by two periods of free choice. Journal of Comparative Psychology, 1936, 21, 67-81.

LATANÉ, B. Gregariousness and fear in laboratory rats. Journal of Experimental Social Psychology, 1969, 5, 61-69.

LATANÉ, B., CAPPEL, H., \& Joy, V. Social deprivation, housing density, and gregariousness in rats. Journal of Comparative and Physiological Psychology, 1970, 70, 221-227.

Latané, B., Schneider, E., Waring, P., \& Zweigenhaft, R. The specificity of social attraction in rats. Psychonomic Science, 1971, 23, 28-29.

Salazar, J. M. Gregariousness in young rats. Psychonomic Science, 1968, 10, 391-392.

Shelley, H. P., \& Hoyenga, K. T. Rearing and display variables in sociability. Psychonomic Science, 1966, 5, 11-12.

Sloan, L. R., \& Latané, B. Social deprivation and stimulus satiation in the albino rat. Journal of Comparative and Physiological Psychology, 1974, 87, 1148-1156.

Stevenson, M., \& Simmel, E. C. Adult social exploration in the rat as a function of pre- and postweaning social experience. Psychonomic Science, 1967, 7, 253-254.

WINER, B. J. Statistical principles in experimental design. New York: McGraw-Hill, 1962.

(Received for publication November 19, 1976.) 